\title{
Ibrutinib Resistance
}

National Cancer Institute

\section{Source}

National Cancer Institute. Ibrutinib Resistance. NCI Thesaurus. Code C147922.

A finding indicating that chronic lymphocytic leukemia does not respond to treatment with Bruton's tyrosine kinase (BTK) inhibitor, ibrutinib. 